\title{
LA MILITANCIA DOCENTE EN LOS TIEMPOS ACTUALES: SIGNIFICANTES POLÍTICOS, TRAYECTORIAS Y EXPERIENCIAS EN LA CIUDAD DE BAHÍA BLANCA (ARGENTINA)
}

Revista Trama

Volumen 7, número 2

Julio - Diciembre 2018

Páginas 9-25

ISNN-1659-343X

http://revistas.tec.ac.cr/trama
Teaching Militancy In The Current Times: Political Signings, Trajectories And Experiences In The City Of Bahía Blanca (Argentina)

Pablo Ariel Becher Canale ${ }^{1}$

Fecha de recepción: 27 de agosto de 2018 Fecha de aprobación: 19 de setiembre de 2018

Becher, P. (2018). La militancia docente en los tiempos actuales: significantes políticos, trayectorias y experiencias en la ciudad de Bahía Blanca

(Argentina), Trama, revista de ciencias sociales y humanidades, Volumen 7, (2), págs. 9-25.

DOI: https://doi.org/10.18845/tramarcsh.v7i2.3940
1. Magister en Sociología, Profesor y Licenciado en Historia por la Universidad Nacional del Sur. Becario doctoral de CONICET en la Facultad de Ciencias Sociales de la Universidad de Buenos Aires. Departamento de Humanidades de la Universidad Nacional del Sur (UNS) -CONICET-. Colectivo de Estudios e Investigaciones Sociales (CEISO). Bahía Blanca, Buenos Aires, Argentina. Correo electrónico: pablobecher@hotmail.com 
Resumen

La presente investigación intenta bucear y analizar los significantes políticos que forman parte de las experiencias de los trabajadores de la educación de un sindicato docente (SUTEBA) en la ciudad de Bahía Blanca. A través de una serie de entrevistas en profundidad, indagaremos en las trayectorias de una serie de participantes seleccionados dentro de estas organizaciones, observando las formas en que se conforma un entramado de sentidos sobre la militancia política y sus formas de hacer y sentir en las últimas décadas (2000-2017). Este trabajo intenta comprender el marco de sentido de las organizaciones políticas y las formas en que socializan tales procesos de participación, politización y acompañamiento hacia la construcción de un ethos militante. De esta manera se describirán las formas en que los actores sociales internalizan repertorios de acción colectiva, comprenden la solidaridad, el trabajo en común y adquieren/contraponen una concientización de la realidad sobre determinados territorios sociales (escuela, barrios, sindicatos, etc.). Por otra parte también observamos las críticas y los procesos de tensión que se generan entre estos participantes políticos y los partidos $u$ organizaciones gremiales a los que adscriben, que pueden llevar a otras vivencias y lógicas de deconstrucción.

Palabras clave: experiencia de organización, militancia, sindicato, conflictividad docente.

\section{Abstract}

The present investigation tries to dive and analyze the political signifiers that are part of the experiences of education workers of a teacher union (SUTEBA) in the city of Bahía Blanca. Through a series of in-depth interviews, we will investigate the trajectories a series selected participants within these organizations, observing the ways in which a network of meanings about political militancy and their forms to make and to feel in the last decades (2000- 2017). This paper attempts to understand the framework of meaning of political organizations and the ways in which they socialize such processes of participation, politicization and accompaniment towards the construction of a militant ethos. This will describe the ways in which social actors internalize repertoires of collective action, understand solidarity, work in common and acquire / oppose a consciousness of reality about certain social territories (schools, neighborhoods, unions, etc.). On the other hand, we also observe the criticisms and tension processes that are generated between these political participants and the parties or union organizations to which they ascribe, which can lead to other experiences and logics of deconstruction.

Keywords: experience of organization, militancy, union, teaching conflict. 


\section{INTRODUCCIÓN}

Las reformas educativas impactaron fuertemente en toda la Argentina y significativamente en la década de 1990, generando consecuencias visibles en el propio sistema de enseñanza (Tedesco \& Tenti Fanfani, 2001). En las últimas décadas, la conflictividad sindical, a nivel nacional, estuvo marcada por la permanencia de niveles importantes de conflictividad del sector de la educación, con huelgas y movilizaciones masivas, superando en muchos casos a otras actividades y ramas económicas (Chiappe, 2010).

Esta investigación pretende comprender las experiencias y significantes políticos ${ }^{2}$ que forman parte de los docentes activos en las organizaciones gremiales, principalmente del Sindicato Únificado de Trabajadores de la Educación Buenos Aires (SUTEBA- Bahía Blanca/ Dorrego) como así también de los marcos de sentido en que se socializan tales procesos de participación, politización y acompañamiento en los repertorios de acción colectiva. A través de una serie de entrevistas en profundidad, se indagará en las trayectorias y las vivencias históricas de diversos actores seleccionados por su perfil participativo, observando las formas en que se articulan un entramado de sentidos sobre la "militancia política" y expresan maneras de hacer/ sentirla/construirla, dentro de distintos territorios sociales (la escuela, la calle, el municipio, su barrio, etc.). Por otra parte, se observarán las críticas y los procesos de tensión que se generan entre estos participantes políticos y los partidos u organizaciones a la que adscriben, que pueden llevar a otras vivencias y lógicas de deconstrucción.

\section{METODOLOGÍA DE INVESTIGACIÓN}

Esta investigación se centrará principalmente en los docentes de diversas modalidades (primaria, especial, secundaria y superior no universitario) que ejercen su labor en escuelas públicas. Los sujetos elegidos no fueron al azar sino que nos posicionamos preferentemente en docentes de escuelas que hayan al menos participado alguna vez en una acción colectiva docente, tratando de visibilizar actores militantes y no militantes dentro o no de organizaciones políticas y gremiales.

Se llevaron a cabo un número importante de entrevistas de tipo semi-estructuradas, mayormente confeccionadas en forma individual. A su vez, estas entrevistas se complementaron con el análisis de diversas fuentes escritas de distinto origen (fuentes periodísticas, publicaciones de las organizaciones, volantes, audios de otras entrevistas, archivos de radiodifusoras locales, entre otras).

La entrevista, como construcción cooperativa- conflictiva de sentidos entre sus participantes, es una vía de acceso a muy diversas problemáticas que encarnan los sujetos de análisis. La memoria se transforma en un registro escrito muchas

2. Se retoma el sentido del término significantes políticos tal como lo utiliza Martín Retamozzo (2007) en varios de sus trabajos sobre subjetividades colectivas. 
veces transcripto provisoriamente, abierto y parcial, donde las expresiones colocan en tensión lo que el otro narra y lo que el/la investigador/a analiza, produciendo una nueva reflexividad. Desde una perspectiva constructivista, la entrevista es una relación social de construcción de saberes y donde se muestran los repertorios de eventos meta-comunicativos de las comunidades de hablantes (Vasilaschis, 2007).

La estructuración de las entrevistas partió de un cuestionario básico y flexible que se llevó por escrito a cada una de las entrevistas. Se realizó una secuencia de preguntas en torno a tres ejes esenciales: 1) la trayectoria biográfica y laboral; 2) su mirada acerca de los procesos de desestructuración en las condiciones de trabajo y de salario docente; 3 ) la especificidad de lo político dentro de las organizaciones sindicales/ políticas en la docencia y 4) sobre los conflictos y métodos de lucha docente. Esta línea metodológica fue el parámetro general en la realización de los encuentros.

La idea central de las entrevistas fue analizar una serie de significantes (conceptos/palabras estructurantes de las experiencias subjetivas) que aparecen en las prácticas sociales de los sujetos, así como también de la exploración de esas experiencias de politización ${ }^{3}$ dentro de las trayectorias individuales/ colectivas que movilizan a la participación. Por otra parte la investigación aborda la percepción de los docentes en torno a su propio trabajo y la subjetivación que realizan de su situación como profesionales o como trabajadores (o ambas).

\section{EL TRABAJO DOCENTE EN BAHÍA BLANCA: ASPECTOS CARACTERÍSTICOS DE UNA SITUACIÓN HISTÓRICA}

La ciudad de Bahía Blanca se ha caracterizado principalmente por ser una ciudad de servicios y actividades comerciales, con un enclave industrial relacionado con el polo petroquímico y la exportación de productos agropecuarios. El rubro servicios sociales y comunitarios dentro del Encuesta Permanente de Hogares (EPH) abarca a una gran cantidad de actividades, entre ellas la docencia, que creció a una tasa elevada en la ciudad. De acuerdo a las estadísticas brindadas por la provincia de Buenos Aires, en Bahía Blanca existen en la actualidad más de 400 establecimientos educativos (obviando el ámbito universitario) en todas las ramas y modalidades, que captan casi 100 mil alumnos en total. Con respecto a las modalidades de gestión, en términos agregados podría señalarse que aproximadamente un cuarto de las instituciones de educación es de gestión privada, mientras que el resto se encuentra completamente a cargo del Estado. 
Existen diferentes maneras de remunerar el trabajo de los educadores: en algunos casos se remunera el cargo docente, en otros casos el pago se efectúa de acuerdo a las horas cátedra (40 minutos de clase o 60 si son módulos) que cada docente tiene en los distintos establecimientos educativos, de modo tal que el salario que pueden obtener mensualmente se relaciona con la carga de actividad que cada profesor tenga. Se ocupan en la ciudad de Bahía Blanca alrededor de 5 mil docentes en los niveles primario, inicial, secundaria y superior no universitario, con un porcentaje de agremiación de más de un $80 \%$, repartidos entre el Sindicato Unificado de Trabajadores del Estado de Buenos Aires (SUTEBA), la Federación de Educadores Bahienses (FEB), el Sindicato Argentino de Docentes Particulares (SADOP), la Unión de Docentes Argentinos (UDA), la Asociación de Magisterio de Enseñanza Técnica (AMET) y UDOCBA (CREEBA, 2016). Algunas de ellas se encuentran adheridas a CTERA ${ }^{4} \mathrm{y}$ a otras centrales sindicales generales como la CGT y la CTA.

Los sucesivos ajustes fiscales y recortes presupuestarios desde fines de la década de 1980 posibilitaron la introducción de la conflictividad docente como un tema importante en la agenda de la protesta social. Entre 1994 y 2008, los docentes a nivel nacional protagonizaron 845 huelgas que representaron el $28 \%$ de las huelgas totales de ese período, a la par de que se da un proceso de articulación con el conjunto del movimiento obrero (Gindín, 2006).

Las grandes luchas contra las reformas educativas y la implementación de la Ley Federal de Educación (Donaire, 2009) de los años noventa se sintetizaron en el nacimiento de una nueva fuerza social dentro de la ciudad que generó alianzas políticas entre los sectores estudiantiles, docentes de distintos niveles, no docentes, empleados estatales y un sector importante de la población excluida (Becher, 2018). En este sentido es importante destacar que muchas de las huelgas y movilizaciones llevadas a cabo por los docentes recibieron el apoyo del movimiento obrero organizado, no sólo en la década de 1990 sino también posteriormente.

Los sindicatos de la educación siempre han tenido diferencias internas en cuanto a los métodos de lucha y la concepción del Estado y los actores económicos. En este sentido, la historia de la conducción de SUTEBA estuvo atravesada por ambivalencias y contradicciones ${ }^{5}$. El apoyo de SUTEBA (conducido por la Lista Celeste) a la Alianza (organización gestada entre dos partidos políticos, UCR y FREPASO) junto con un sector de Asociación Trabajadores del Estado (ATE) en 1997 y 1999 y la invitación a contener el conflicto social en forma defensiva le valió la conformación de pequeños grupos de docentes disidentes que comenzaron a crecer y a generar resistencias internas a nivel local.

Entre 1994 y 1997 se gestó un importante proceso de resistencia, en la ciudad de Bahía Blanca y también a nivel nacional, sobre todo de los llamados "docentes indignados", muchos de ellos provenientes de la Lista Marrón (ligada a la izquierda), que realizaron acciones protesta contra las reformas educativas enfrentando la conducción local ${ }^{6}$. El año 2000 se caracterizó por el ascenso de la conflictividad en el movimiento docente que comprendía la necesidad de ir generando un apoyo más amplio de los sectores populares y obreros, en la búsqueda de condiciones que permitieran un cambio social y económico en el país. Las formas de acción colectiva se aunaban en una metodología similar en todo el país: asambleas populares para decidir colectivamente, realización de piquetes y cortes de calle en la entrada de las empresas o en las instituciones públicas, ataques a las fachadas de los edificios, toma de establecimientos, manifestaciones callejeras y escraches públicos.

En el año 2001, frente a la falta de pagos, los graves recortes presupuestarios, la continuidad en la precarización laboral, la falta de respuestas de las autoridades políticas comenzó a gestarse un gran movimiento docente que empujo la lucha social en la ciudad. En julio y agosto de 2001 se produjeron en la ciudad de Bahía Blanca una serie de movilizaciones docentes, acompañadas de múltiples sectores populares, ante los recortes en el presupuesto, la difícil situación de la educación pública y el panorama crítico de los comedores. Lo que comenzó con una retención de servicios se convirtió en un paro por tiempo indeterminado, sumando organizaciones nacionales y hasta privadas del sector docente (Carabajal Figueroa, 2001:4-5).

El 22 de agosto del 2001 se generó un fenómeno de enorme movilización la ciudad llamado "Escuelazo". Convocado por el Frente Gremial Docente (SUTEBA, FEB, SADOP principalmente) y ADUNS, tuvo el apoyo de padres, madres, alumnos y auxiliares de

4. Confederación de Trabajadores de la Educación República Argentina conformada en 1973 es la principal confederación de organizaciones gremiales docentes en la actualidad. Agrupa más de 24 sindicatos provinciales y de la Ciudad de Buenos Aires, y reúne dos terceras partes de los afiliados a las cinco organizaciones reconocidas para las negociaciones colectivas nacionales (paritarias sancionadas efectivamente desde 2006 por la ley 26075 de financiamiento educativo).

5. Entrevista a Ernesto, docente y dirigente sindical, realizada por Pablo Becher (PB) a través de correo electrónico, 27 de febrero de 2017.

6. Entrevista a María, realizada por PB el 18 de abril de 2015. 
la educación, reuniendo aproximadamente a 15.000 manifestantes. Marcharon desde el municipio por diversas calles céntricas, y retornaron al municipio. Se sumaron habitantes de los partidos de la zona. Se llevaron banderas y carteles alusivos de los establecimientos. Participaron delegaciones de jubilados y pensionados, judiciales, bancarios, camioneros, docentes universitarios, empleados estatales, entre múltiples actores sindicales (La Nueva Provincia, 2001: 4-5). Sin embargo, la conflictividad comenzó a menguar cuando desde la conducción provincial del sindicato docente se comunica un principio de conciliación con el gobierno. El 28 de agosto del 2001 Hugo Yasky, dirigente del SUTEBA Provincial, perteneciente a la lista Celeste, y de la CTA, decidió levantar el paro y comenzar las negociaciones con el gobierno provincial. Se"normalizaba"la situación, pero dentro del SUTEBA Bahía blanca se generaron tensiones por la decisión. Docentes, padres/madres y alumnos (unas 300 personas), reunidos en asamblea, pidieron al sindicato mayor transparencia y democracia en sus decisiones. Un grupo de docentes y padres disidentes expresaron que nunca se tuvo en cuenta su posición y entregaron un petitorio con demandas al sindicato (La Nueva Provincia, 2001: 6).

Todos estos eventos históricos fueron la antesala del Argentinazo en Bahía Blanca. La conformación de la Agrupación Docentes Indignados, como docentes autoconvocados ${ }^{7}$ de la dirección del SUTEBA, en octubre de 2001 engarzó con el movimiento de padres, madres y docentes independientes como una forma de presionar a la lista Celeste para que asumiera un posicionamiento político y tome medidas concretas frente al gobierno de la Alianza. Se conformó con un posicionamiento antiburocrático que expresaba la indignación del conjunto popular ante la situación del ajuste.

"Docente indignados se conforma en el período posterior a las 2 grandes movilizaciones de agosto 2001 en el marco del paro provincia en educación. En el Suteba existía una oposición histórica (la lista marrón que se había formado en el 88), cuya principal virtud fue visualizar claramente que había que dar una forma organizativa y programática a esa impresionante irrupción de la base docente que sale de la huelga con la clara convicción que la conducción celeste provincial y la local la habían traicionado (...) Es decir Indignados es el resultado de la confluencia de la "vieja Marrón" con el nuevo activismo que irrumpe en la huelga de Suteba" 8 .

8. Entrevista a Ernesto, idem. ant.

9. Entrevista a Ernesto, idem. ant.

10. Entrevista a María, idem. ant.
El Escuelazo constituyó una de las movilizaciones más grandes de la historia de Bahía Blanca, y fue mucho más de una manifestación docente: se trató de una respuesta firme de las bases, del movimiento asambleario por escuelas, de la participación de padres y madres preocupados por la situación de la educación. Se puede caracterizar como una experiencia de movilización popular y de base que expresó mucho más que el encuadre sindical que lo impulsaba y que puso de manifiesto el anacronismo entre lo que se supone que es la escuela y lo que es en realidad (Rezzutti, 2011: 4). Los trabajadores de la educación fueron convirtiéndose en el sector más dinámico dentro del conjunto asalariado e impulsaron en todo momento la unidad entre distintos trabajadores y una contracultura de la resistencia, que vinculaba el movimiento con la crítica al Banco Mundial y los planes del Fondo Monetario Internacional ${ }^{9}$.

El sector docente fue también el eje de la articulación obrera-popular-estudiantil, actuando como intelectuales/representantes activos dentro de un proceso más amplio de lucha de clases. Su papel mediador entre trabajadores estatales y privados incluyendo a los desocupados, su adherencia a principios de izquierda - definidos en torno a una cultura de resistencia frente al capitalismo neoliberal - y su capacidad de canalizar las ideas y expresiones de diversas fracciones obreras en un plan de lucha, convirtió a los docentes en un sector crucial en el proceso de masificación del conflicto social en Bahía Blanca.

En 2003, se desarrollan los comicios del gremio de SUTEBA, donde votaron unos 1.800 afiliados, que eligieron una nueva conducción local. La elección demostró el éxito de los docentes indignados y opositores que supieron leer la voluntad política de las bases y actuar acorde a los tiempos históricos. Es así que triunfa la lista Granate con la mitad de los votos aproximadamente. El triunfo reivindicaba a un amplio sector docente que se había plantado fuertemente contra la política del sindicato, presionándolo a tomar parte de las luchas que se estaban dando en otros sectores ${ }^{10}$.

En este sentido, se concluye que el sector docente fue, por sus características, el tamaño de su sindicato y su historia de lucha, el eje articulador alrededor del cual se conjugaron el movimiento estudiantil contestatario, los diversos elementos populares en los barrios y fábricas, y la comunidad educativa (padres/madres, alumnos y auxiliares), que se unió momentáneamente en esos años para 
enfrentar al gobierno aliancista, aliado a la burguesía internacional y nacional, tratando de expresar una alternativa política.

En el año 2003, bajo un nuevo proceso de acumulación capitalista iniciado durante los gobiernos de Néstor Kirchner (2003- 2007) y Cristina Fernández (2007- 2011), se produce una recomposición de las formas de lucha obrera. Estos dos períodos estuvieron marcados por una reactivación económica y una serie de cambios en materia fiscal y salarial que mejoraron la situación de empleo pero mantuvieron altas tasas de informalidad y precarización laboral, intensificándose las problemáticas asociadas a su caída en la proporción en el ingreso nacional, una acentuación de los despidos y un crecimiento de la conflictividad laboral (Svampa, 2008; López \& Cantamutto, 2013). Como consecuencia de esta nueva configuración cobró protagonismo el conflicto gremial, caracterizado por una creciente intervención de las cúpulas de la CGT (Confederación General del Trabajo) en la negociación salarial, posibilitando el retorno a las negociaciones colectivas. Se produjo a su vez un incremento del activismo de base de diversos sectores de trabajadores, que en forma independiente de las direcciones sindicales, $y$ a veces en oposición, se organizan en comisiones internas y cuerpos de delegados.

En el ámbito educativo, la sanción de la Ley de Financiamiento 26.075/05 fue eje central de la política que dispuso el gobierno de Néstor Kirchner en este sector. La misma introdujo mecanismos para la inversión sectorial entre los distintos niveles de gobierno con el objetivo de incrementar las erogaciones que la componen desde el 3,9\% del PBI 2003, alcanzando a un 6\% del PBI en el 2010. En el año 2006 se sancionó un nuevo marco para el sistema educativo, con la Ley de Educación Nacional que sustituyó a la Ley Federal de Educación del año 1993 (Chiappe, 2010: 316). Con el decreto presidencial 137 del año 2005 se reconoció la vigencia de la Ley de jubilaciones docentes. En esta línea continuaron las políticas estatales implementadas por el gobierno de Cristina Fernández de Kirchner hasta la consolidación de las negociaciones colectivas a nivel nacional (Paritaria Nacional de marzo 2008). Estas políticas se dieron en el marco de una convergencia de CTERA con el gobierno que signó este período. La CTERA fortaleció su rol como actor central en la puja educativa. La coalición con el gobierno tendrá dos consecuencias fundamentales: por un lado la ausencia de paros nacionales, y por otro, el cambio en la modalidad de protesta que pasa a ser mucho más sectorial y con fuertes discontinuidades.
En Bahía Blanca, el cambio de gobierno a nivel local por uno peronista en 2003, inició una nueva fase, dando lugar a la conformación de nuevas fuerzas sociales, al tiempo que los trabajadores de la educación, de la administración estatal, salud y empresas privadas iniciaron una serie de huelgas sectoriales por el aumento salarial, en un contexto signado por la devaluación y la salida de la crisis económica. Los docentes a nivel local tuvieron una relevancia fundamental como actores aglutinantes de oposición política al kirchnerismo y al propio sindicato central, con un conjunto de demandas que superaban lo meramente reivindicativo e intentaban discutir puntos fundamentales como la precarización laboral, la negociación colectiva y la represión estatal. A partir del año 2006, las conducciones opositoras a la llamada lista celeste conformarán una agrupación más amplia denominada Encuentro Colectivo que compartieron criterios de organización y principios básicos, basados en el pluralismo, la organización de base, clasismo, renovación de cargos y combate constante contra la burocratización de las conducciones (Blanco, 2010).

En los últimos dos años desde la asunción del gobierno de Cambiemos y la presidencia de Mauricio Macri (2015- actualidad), la situación en educación ha empeorado notablemente: al desfinanciamiento por ajuste, se sumó un avance sobre el estatuto docente, el cierre de los bachilleratos de adultos y de escuelas especiales, planes que cercenan la carrera docente y aumentan su competitividad, la falta de un planeamiento y financiación para infraestructura y el ataque sistemático a los sindicatos docentes. Todo en un contexto de recesión, nuevo endeudamiento con el FMl y una crisis inflacionaria que disminuye las posibilidades de obtener un salario real acorde a la canasta básica.

\section{DIMENSIONES DE ANÁLISIS DE LAS ENTREVISTAS}

La situación educativa en América Latina y el Caribe ha estado atravesada por múltiples contradicciones que limitan su expansión y crecimiento. Estos limitantes tienen que ver con los grandes procesos de desigualdad económica y social que han marcado históricamente la región, con "democracias débiles" y fuerzas corporativas muy fuertes y la persistencia de la exclusión social y flexibilidad laboral que tiende a 
generar una masa de población sobrante con escasas posibilidades de empleabilidad permanente y estable. Al problema de la accesibilidad, se le ha sumado la baja "calidad educativa" (por las propias reformas educativas), problemas de infraestructura, carencia de tecnología y una pobre inversión en educación (Gentili, 2013). Esto ha provocado el aumento de la matrícula en educación privada y el deterioro de la actividad docente que ha observado un proceso de empobrecimiento, pauperización y proletarización extendido, principalmente en países como Argentina.

Si la democratización de la escuela no fue acompañada por parte del Estado nacional de una democratización efectiva del derecho de la educación para las capas más pobres de la sociedad, fue porque la educación se convirtió en un privilegio que diferencia y promueve la competitividad entre individuos en el sistema capitalista neoliberal (Gentili, Suarez, Stubrin \& Gindin, 2004). Las luchas sindicales, de movimientos sociales y de organizaciones civiles y políticas en torno a esta situación han intentado invertir esta situación, intentando buscar marcos legales que aparen mejoras en las condiciones laborales y en el estatuto docente (Jaimovic, Migliavacca, Pasmonik \& Safocarda, 2004).

Si bien los temas en disputa más importantes entre docentes, sindicatos y Estado se relacionan en muchos casos con las condiciones salariales y laborales, el presupuesto o la falta de incentivos para el sector, nos resulta interesante indagar en la nociones de precariedad, sus sentidos y vivencias; la pertenencia al mundo sindical y por último la conflictividad y los métodos de lucha, como dimensiones de análisis que reflejan realidades históricas. ¿De qué forma los docentes sienten, reflexionan, perciben y actúan en sus territorios sociales cuando se encuentran atravesados por estas problemáticas? ¿Qué los moviliza a actuar pasivamente o activamente? ¿Qué pensamientos e ideas construyen y trasmiten? ¿Cómo conciben la lucha colectiva y las organizaciones gremiales?... Algunas de estas preguntas fueron los móviles fundamentales que surgieron en las entrevistas abiertas realizadas a docentes de distintos niveles educativos entrelazados en un marco histórico donde se refleja el presente del gobierno de Mauricio Macri con el pasado más cercano de los '90. A continuación se irán señalando dimensiones y significantes fundamentales de las diversas experiencias que los sujetos rememoran y construyen como parte de sus reflexiones pasadas y presentes.

\section{Dimensión 1: Precarización laboral}

Cuando hablamos de precarización laboral nos referimos a un proceso social que se asiente en el desarrollo histórico de la acumulación capitalista y que tiene como características centrales la inestabilidad en la ocupación, flexibilidad y falta de condiciones mínimas para la seguridad del trabajador o trabajadora. Los empleos precarios son "generalmente lícitos, establecidos válidamente por leyes o decretos y de esa manera se los naturaliza, aunque tengan repercusiones negativas sobre el sistema de relaciones de trabajo y sobre la vida y la salud de los trabajadores" (Neffa, Brown \& López, 2010: 5).

Durante la década de 1990 los salarios reales se redujeron y el trabajo se precarizó, producto de sucesivas modificaciones a las regulaciones laborales y a la intensificación de la explotación patronal/estatal. Esta situación continuó fuertemente luego del 2002, aunque tendió a atenuarse frente a un crecimiento económico que disimulaba expectativas diversas. La protección brindada por el estatuto permitió cierta estabilidad al trabajador de la educación, lo cual garantizaba derechos adquiridos. Sin embargo, la baja inversión presupuestaria y el déficit en la infraestructura no fueron las condiciones efectivas para el desarrollo de una mejora en la condición laboral.

Daniela tiene 35 años. Es docente de lengua y literatura egresada de un instituto terciario de formación docente. Proviene de una familia mapuche. Trabaja en tres turnos, dentro del ámbito secundario, y realiza actividades administrativas además de su propia profesión. Su día empieza y termina en la escuela.

“La precarización laboral es una situación desgastante, porque si a las condiciones de infraestructura, a la económica, vos le sumas que las escuelas no están en condiciones de efectuar gastos mínimos, para resolver necesidades básicos, y por otro lado tenés una mutilación, porque todo es un pin pon... es todo como un combo (...) te provoca una indignación permanente" ${ }^{11}$.

Sus cargos siempre estuvieron vinculados a escuelas de barrio periféricas, donde la realidad es otra, marcada por el sentido de pertenencia en medio de una gran desigualdad. Ella siempre fue una activa defensora del trabajo docente. Tuvo una gran influencia en su formación académica de parte de compañeros/as y docentes que la incentivaron a la crítica. Los primeros momentos de conflictividad, en los cuales participó, tuvieron que ver con las condiciones de trabajo en las que se veía inmersa. La lucha docente

11. Entrevista a Daniela, realizada por PB, 26 de abril de 2018. 
fue parte de su acción cotidiana y ha acompañado en varias oportunidades al sindicato de SUTEBA, aunque sin pertenecer a ninguna lista.

Olga tiene 51 años y se recibió hace cinco años como profesora de literatura. Trabajó muchos años en una editorial. Como Daniela, trabaja tres turnos que apenas le alcanza para poder estar un breve rato en su casa. Principalmente desarrolla su trabajo en el ámbito secundario aunque también dedica su tiempo al bachillerato de adultos. Viaja constantemente para poder ejercer la docencia en lugares remotos de su vivienda. Para ella la precarización no solo se encuentra relacionado con la disminución del salario sino con atender a múltiples demandas que generan frustración y desvalorización permanente.

"El salario no alcanza para vivir...trabajar tres cargos lo que significa trabajar mañana, tarde y noche para poder vivir, y mantener a la familia: no alcanza... cada vez está peor vivir con un sueldo docente... (...) es una cualidad que se está agudizando cada vez más... para vivir dignamente...uno sabe lo que es el sueldo docente aun antes de elegir la carrera...tenemos que trabajar muchas horas y en muchas escuelas: para poder tener cierta cantidad de horas tener que andar todo el día...y no solamente que vos vas a la escuela sino el tiempo que vos empleas para ir de escuela en escuela. En el caso mío que no tengo auto asi que voy en colectivo. $Y$ tengo que tener una diferencia de una hora entre escuela y escuela para poder ir $(\ldots)^{\prime \prime 2}$.

Ante las condiciones pésimas, Olga expresa"el estudiante y el docente se sienten de segunda", donde se afecta gravemente la calidad de enseñanza con educadores que padecen graves problemas de salud psicológica y física. Olga fue presidenta de un centro de estudiantes en su juventud y la militancia formó parte de su estilo natural de entender la participación política. Sin embargo es muy crítica del sindicato, que si bien lo considera "una organización que vela por los derechos de los trabajadores", también observa su falta de practicidad para resolver los problemas cotidianos de los docentes.

Marcelo con 19 de antigüedad docente permanece firme dentro de la educación como elección laboral. Sus estudios fueron realizados en un terciario donde además hizo otras carreras. La militancia religiosa salesiana le permitió encontrar naturalmente su vocación docente. Con un cargo de doble turno principalmente en el nivel primario, Marcelo ha trabajado en las escuelas públicas de barrios marginales de la ciudad. Pero sus comienzos fueron en una escuela privada. Estas experiencias le ayudaron a corroborar una imagen de los dos ámbitos:

El ámbito privado da la sensación que es más ordenado, que hay ciertos elementos que vos en lo público no lo tenes, entonces, te da como otro enfoque diferente a lo que vos podes vivenciar en otro trabajo como en lo público (...) yo le decía a mi amigo preceptor que ojala nunca me acostumbre a esta situación...porque hay como una comodidad de tener muchas cosas. Y te vas dando cuenta de los lugares en condiciones, te vas dando cuenta en lo que vos pedís cuando trabajas a los chicos y las familias y la respuesta que hay...que en el Estado es todo complicado cuando vos trabajas....en el estado es todo como más al ritmo de nosotros, lo que vos podes ir haciendo, lo que vos podes ir aportando o consiguiendo para poder avanzar en lo que querés avanzar (...) es muy la frase "lo atamos con alambre"..." ${ }^{13 .}$

Para él, la lucha docente se estructura a través de la búsqueda de un reconocimiento de dignidad, en espacios donde la precarización laboral aparece como una realidad vívida. "¿Qué función cumple la escuela? Esa es la pregunta que nos hacemos como docentes en medio de realidades complejas que repercuten en el aula, ¿Esta para enseñar o se encarga de lo social?"

La realidad del trabajo del docente para Marcelo se encuentra en todo momento atravesada por "un gran desgaste mental, también físico, pero principalmente mental, que agobia y cansa, donde la mujer sufre el doble, por la carga doméstica asignada en la sociedad patriarcal". Encontrar momentos para uno mismo se vuelve una odisea, en medio de la intensificación de la tarea docente.

Alejandra estudio magisterio y educación especial en un instituto terciario. Siempre estuvo asociada a este nivel ya sea como trabajadora social o como docente. Ha trabajado 29 años en escuelas especiales y conoce de qué se trata la precarización.

“En principio para mí la precarización laboral tiene que ver con el salario, porque es la manera que tiene el Estado de demostrar que la tarea que realizamos es una tarea que es válida para la sociedad en su conjunto y si esta tarea no está bien remunerada es una tarea que no está reconocida por el Estado (...) y lo otro tiene que ver con que nosotros nos somos consultados en términos generales con la educación que queremos para esta sociedad, nosotros que somos profesionales de la educación, maestros maestras profesores y profesoras, nos somos consultados en 
las leyes redactan y aplican estos intelectuales, gente que seguramente está capacitada, o bien estudiosos pero que difícilmente hallan pasado muchos años de su vida en la escuela propiamente dicha...ahí tampoco tenemos injerencia...después están las cosas de todos los días que nos precarizan la tarea, esto de que tenemos que andar en diez mil escuelas para, de un lado para otro, para consumir todas las horas que necesitamos, pero eso es consecuencia de que no tenemos un buen salario, el tema de las condiciones de infraestructura $(. . .)^{\prime 14}$.

En este sentido precarización es una cualidad que define la vida cotidiana docente, que no se asienta solo en lo material, sino también en su propio reconocimiento como sujeto. Aquí nos detenemos para pensar en las formas en que la conflictividad se vuelve en un factor de re-significatividad de sí mismos, como personificación trabajadora.

\section{Dimensión 2: ¿Cómo se concibe al sindicato docente?}

Alejandra, además de maestra, es militante de la lista granate de Bahía Blanca asociada en la actualidad a la Lista Multicolor (izquierda) a nivel provincial. Su descubrimiento de la militancia tuvo fecha a fines de la década de 1980, principalmente en oposición a las ideas más tradicionales y conservadoras que según ella portaba de haber sido parte de un pueblo del interior bonaerense (Pigüe). Con el tiempo y participando de la actividad docente, ella se contactó con sectores disidentes del oficialismo en SUTEBA y se unió a la lista marrón. Allí organizó su actividad sindical estableciéndose como delegada escolar. Para ella ser docente es ser un profesional de la educación, pero a la vez un trabajador fuertemente atravesado por distintas tareas que le han impuesto desde la realidad social.

Según su visión, el sindicato y su concepción del mismo fueron construcciones que se armaron y reconvirtieron en un aprendizaje permanente, al sintetizar múltiples experiencias de trabajo con sus propios/as compañeros/as. Para ella, sindicato y construcción política van de la mano, y son inseparables, aunque entiende que dentro de la docencia "cuesta mucho hacer entender este binomio". Ella se pregunta por la resistencia de los docentes a equiparar sindicato con política, como una materia pendiente que merece un tratamiento especial a la hora de ponerlo en discursos y acciones.

"A mí me parece que todavía quedan resabios en el sector docente de que la tarea que vamos a cumplir en las escuelas es una tarea de formación de enseñanza, de que tenemos que ser bien reconocidos por las familias de nuestros alumnos y alumnas y pareciera que cuando uno se involucra en determinadas cuestiones que tienen que ver con la política, esto no está bien visto por algún sector de la comunidad en la que nosotros estamos dando clases... y además creo que a esto se suma, que el sector docente en términos generales, forma parte de una clase media que todavía no fue demasiado empobrecida entonces no hay una plena conciencia de clase en la mayoría de los compañeros y compañeras, que los lleve a pensar que tenemos que hacer política para defender nuestros derechos. $Y$ para mantener este lugar de educadores. $Y$ hablo no solamente de los salarial sino de nosotros como protagonistas de las ejecuciones o de la elaboración de las leyes, de la enseñanza o educación que queremos en nuestras escuelas, para el país, entonces esa franja todavía cree que nosotros no somos una franja que tenemos que pelear por derechos, (...) por eso también hay un montón de compañeros y compañeras que no se animan a participar de una movilización porque tienen miedo, o vergüenza de que alguien los pueda ver manifestándose, con banderas y bombos (...)" 15 .

Para Daniela el "sindicato es una organización de trabajadores que permite cuidar los derechos pero también plantea las obligaciones que se deben cumplir". Desde su postura, las banderas políticas partidarias no deberían prevalecer en el ámbito sindical. La empatía con la población en torno a las acciones colectivas resulta de un trabajo ardua de reconocimiento, "que no se tiene desde la mirada salarial, sino del trabajo día a día". Las asambleas convocan a un sentido de democratización de las decisiones pero muchas veces se vuelven espacios de declamación partidaria que no lleva a ninguna resolución práctica.

Esta situación se ve confirmada diariamente, por los docentes no militantes de agrupaciones partidarias, que prefieren que los espacios de discusión sean espacios más bien de planteos sobre la propia "realidad docente". El caso de Marcelo lo sintetiza de esta forma. Su participación gremial fue paulatina, viviendo más lo cotidiano en las aulas. Cierto día comenzó a pensar en porque era importante hacer respetar sus derechos. "Ya no pensaba el paro como un día para estar en su casa, sino para transitarlo activamente..."

Él piensa el sindicato como una organización que respalda a los trabajadores, más allá de su composición diversa, rescata la democracia interna y lo valores que transmite. Pero tiene muchas críticas en torno a su funcionamiento. La defensa gremial es importante pero "a veces las convicciones políticas

14. Entrevista a Alejandra, realizada por PB, 7 de mayo de 2018.

16. Entrevista a Alejandra, ídem. 
se colocan en contradicción con las problemáticas docentes...no se escuchan y a veces el docente se siente aplastado por la pesadez del partido político".

"Yo empecé a participar cada vez más, iba a las marchas iba a las asambleas, de hecho soy delegado del turno mañana (...) la participación, estar, poder escuchar, debatir, eso es lo que te da mayor seguridad cuando vos haces un reclamo, o querés hacer una medida o cuando vos querés dar una razón de porque haces lo que haces, o dar tu idea y expresarla (...) escuchando otras voces, eso es lo que te posibilita comprender (...) Pero en el ámbito docente es complicado, por un lado está el docente que participa en el sindicato porque quiere ser escuchado desde ese lugar como docente, más allá de la idea política que tengas...pero también están aquellas personas que tienen una convicción política, y son docentes...entonces en muchos casos, esa convicción política pesa más que ser docentes, (...) Me ha pasado escuchar gente enardecida con mucho fervor porque participa de un partido político, pero jamás lo escuche hablar de su idea como docente, jamás lo escuche compartir como planifica algo, jamás lo escuche que problemas tiene dentro del aula para resolver, jamás escuche como quiere cambiar cosas en su escuela y poder acompañar o como resolver... nada, hay como un fervor más grande que la realidad que nos toca vivir (...)Y eso hace que muchos docentes sean reacios a ir a las asambleas (...) [Los docentes militantes] hablan sobre la estructura de su partido político, como una bajada a nivel político que se lleva al ámbito docente...y eso insiste sobre esa situación y ahí es cuando muchos docentes que no participa de ese movimiento, o cualquier grupo político, sienten rechazo. $Y$ en algunos casos genera cansancio (... ${ }^{16}$.

Iván es profesor de historia recibido de la Universidad Nacional del Sur. Durante un tiempo trabajo y conoció la explotación en carne viva, hasta que finalmente sus padres lo ayudaron a mantenerse para poder dedicarse a terminar la carrera. Comenzó a trabajar mientras estudiaba. Sus primeros acercamientos con la política fueron alrededor del comunismo y de la lectura de guevarismo. Allí fueron sus primeros pasos en el Partido Revolucionario de los Trabajadores, aunque terminaron siendo truncos frente a la imposibilidad de generar una masificación del proyecto a nivel local. Finalmente, asentado en el trotskismo decidió participar en el FOS- PSTU (izquierda morenista) "Ahí fui dando mis verdaderos pasos de militancia más estructural, ir al sindicato, ir a SUTEBA, dar una pelea dentro de las bases...." La militancia diaria se convirtió en parte de su coherencia entre el pensar, decir y hacer. Para ello debía trabajar en el socialismo dentro de la docencia, "desde la propia base, habla desde lo cotidiano y tratar de enlazarlo con la idea de que la solución de esto es el socialismo, una visión política" $^{17}$

Finalmente su militancia, por diversas discusiones y planteos con los cuales no congeniaba con el PSTU, decanta en el Partido de los Trabajadores Socialistas (PTS) y en la agrupación docente La Marrón. La posibilidad de canalizar sus inquietudes y resolverlas democráticamente, su visión internacionalista y clasista, y la formación dentro de una estructura de partido le dieron un encuadre importante para su posterior continuidad dentro de la organización. Es allí donde define su idea de sindicato.

"En teoría el sindicato debe defender los intereses de los trabajadores...y en teoría porque en realidad en los hechos, los sindicatos de todos los trabajadores, son instrumentos del gobierno de turno que sirven para imponer las políticas de turno (...) nuestro sindicato docente a pesar de que es más democrático que otro, no escapa de su realidad (...) Pero a pesar de que es una herramienta del sistema capitalista si uno lucha por expulsar a esas direcciones que son en última instancia traidoras de los trabajadores, el sindicato es una herramienta de lucha uno puedo hacerlo partiendo desde las bases de comisiones directivas...desde una escuela como delegado, desde una seccional o incluso desde varias seccionales se puede ganar un sindicato...pueden ser utilizadas esas herramientas como herramientas de lucha para hacer avanzar a los docentes sino también a otros trabajadores..." ${ }^{18}$.

Para Iván la relación política y sindicato son fundamentales y se correlacionan mutuamente. La experiencia de lo cotidiano, no puede desligarse del contexto socioeconómico y político. Pero en éstas entrevistas se expresaron varias formas de pensar el sindicato como institución dentro del marco capitalista, como herramienta legal de los propios derechos como trabajadores o como un espacio de lucha de clases. Estas situaciones se perciben en los discursos y acciones de los individuos que participan en la docencia. Pero una cuestión que merece una apartado es la metodología de lucha propuestas y dispuestas por estos actores.

\section{Dimensión 3: Métodos de lucha}

Analía empezó a estudiar el profesorado en Historia en 1993. Terminó de estudiar en el año 2000 en medio de una fuerte crisis política, económica y social en la Argentina. Esta situación la hizo comenzar su militancia vinculada al mundo estudiantil universitario

16. Entrevista a Marcelo ídem.

17. Entrevista a Iván, realizada por PB, 17 de mayo de 2018.

18. Entrevista a Iván ídem. 
y principalmente a las luchas con la instalación de la ley de educación superior en 1995. Allí aprendió los vaivenes de la política y a reconocer las diferencias dentro de las agrupaciones. Con el paso del tiempo, fue invitada a participar de reuniones de la Lista Marrón, con la cual encontró un lugar inmediato donde confluían sus ideas. Viejos y nuevos militantes comenzaron a compartieron ideas sobre el compromiso político, con propuestas pedagógicas alternativas que invitaban a desafiar las formas dadas, reflexionando sobre la visión del ser docente como trabajador/a. Se enfrentaba principalmente contra "los métodos burocráticos [de la conducción de SUTEBA- Celeste, la falta de participación, y el fuerte control del sindicato, que llevaba a pensar la disidencia como un problema" apostando a la unidad interna para no debilitar la organización.

A partir de allí y como delegada de su escuela, Analía va a acentuar su vinculación con el gremio adquiriendo una metodología de acción que le permitió pensar en la construcción de otras prácticas sindicales, ligadas a la democracia de base y la horizontalidad en las relaciones.

“En el 2000 fui delegada de la secundaria $n^{\circ} 5$ con un trabajo de base. El trabajo de base en las escuelas es siempre complicado. La propia situación del docente no se visualiza como objeto de políticas públicas, hay una fuerte alienación dentro del mundo docente. El trabajo de base debe servir para la organización y la información de lo que sucede. Rara vez se entra con un discurso duro desde lo ideológico, se debe trabajar en la posibilidad de generar conciencia de clase" ${ }^{19}$.

La constitución de la lista granate, su elección triunfante en el año 2003 y su aprendizaje de las anteriores luchas, formalizan un proceso fundante de un sindicato pluralista que intente dar respuesta al conjunto de trabajadores, independiente de las organizaciones partidarias y de carácter clasista. Con dirigentes que se renuevan en sus cargos y que no dejan de trabajar en las escuelas, se impone la garantía de referentes que no se desliguen de las condiciones de trabajo de sus propios compañeros y que no se desvíen en la burocratización. Ante estos principios inclaudicables se imponen mecanismos de decisión basados en la democracia directa asamblearia, la libre circulación de ideas, el respeto por la diversidad y la elaboración colectiva, dando legitimidad fuertemente al cuerpo de delegados.

Otro tema fundamental que se encuentra en construcción resulta de la incidencia del feminismo en las prácticas entre compañeros y compañeras, que formalizaron un conjunto de cambios importantes en las relaciones, en el lenguaje y en la percepción de las relaciones de género ${ }^{20}$. Estas cuestiones resultan fundamentales frente a cargos directivos ocupados históricamente por hombres, donde primaron sus decisiones y la mujer sindical continuaba ligada a lo doméstico. Las discusiones sobre este punto dentro de los sindicatos y principalmente en SUTEBA generaron fuertes debates, conflictos internos y profundas reflexiones.

¿Cómo lograr un nivel de adhesión en las medidas de fuerza? ¿De qué manera propiciar la unidad de los distintos trabajadores? Esta pregunta insoslayable forma parte del accionar cotidiano de los militantes y no militantes dentro de la organización gremial, amalgamando lo reivindicativo con la política general. El trabajador estatal está situado en una relación de doble subordinación: "por un lado a quien constituye su superior, en la cadena de mando de un ámbito concreto de trabajo por un lado y, por otro, a la norma que lo constituye como funcionario y que define sus responsabilidades como servidor público" (Palomino, 2004: 34- 39). Esta doble relación promueve la politización del sindicalismo docente y su focalización, a veces difícil, por la presión sobre el Estado. Por lo tanto, las acciones conflictivas de los docentes se orientan a la esfera estatal y cobran así connotaciones políticas e, incluso, político-partidarias. La acción sindical y el movimiento político se asocian estrechamente, más allá de la voluntad de los interlocutores. Y en este situación la educación cobra una dimensión más compleja por ser un ámbito de socialización y reproducción social, donde se ejercen demandas profesionalizantes y laborales.

Tanto para Analía como para Alejandra el antídoto esencial contra el individualismo y el ataque mediático contra la docencia en general, se logra a través de la ampliación de las demandas.

"Está bueno cuando uno consigue centrar el reclamo en una necesidad o en una reivindicación que es común a más de un sector de trabajadores... cuando yo veía por ejemplo las enormes manifestaciones que logramos hacer con los médicos fuimos al Hospital Penna, conocimos las unidades sanitarias,(...) y a las maestras les gustaba eso de ir a las marchas de guardapolvo porque estábamos peleando ambos sectores contra un mismo patrón, por reivindicaciones muy similares, en dos sectores de la sociedad que son absolutamente necesarios, como son la salud y la educación, y de la que nadie está ausente, porque todos

19. Entrevista a Analía, realizada por PB, 17 de mayo de 2018 .

20. A su vez mediatizado en la Argentina de las últimas décadas por la lucha para la implementación de la Educación Sexual Integral en las escuelas, las movilizaciones por el Ni una Menos (desde 2015) y la campaña a favor del aborto legal, seguro y gratuito (2005). 
envían sus hijos a la escuela y van a un hospital público, entonces poder pelear juntos con otros sectores de trabajadores es una buena propuesta (... $)^{21}$.

Marcos está estudiando el profesorado de música del Conservatorio de Bahía Blanca. Docente del nivel inicial en jardines públicos comenzó su carrera frente a la necesidad de "bancar la olla" y colaborar con la propia subsistencia de su familia. Padre de una niña pequeña, transita su trabajo más allá de la vocación, y siente la necesidad de dar pelea por mejorar las condiciones de trabajo de sus compañeros. Actualmente milita en Tribuna Docente agrupación que tiene su afinidad con el Partido Obrero, a nivel provincial. "Yo siempre fui muy crítico de SUTEBA, al principio era medio anarquista, criticaba todo pero cuando uno está en la organización del partido uno imprime una política y como querés direccionar el sindicato o para que rumbo tendría que ir (...)".

Para Marcos el hecho de pertenecer al Partido Obrero implica todo un prestigio y una responsabilidad que fue aprendiendo de sus experiencias diarias, compartidas con múltiples dirigentes históricos, leyendo su prensa, debatiendo con sus compañeros, participando en congresos nacionales.

Para él es importante generar un buen canal de diálogo con sus compañeros de base, contarles la verdad, tratando de desenmarañar la información hegemónica. Y trata de "ser cuidadoso", siendo frontal con la realidad, y tratando de articular lo que pasa "a la vuelta de la esquina con los problemas de fondo, nacionales e internacionales, expresando la realidad, tirando un planteo, profundizando o no un debate" 22 .

Desde su postura formada por la militancia partidaria existen muchas veces críticas a la línea política, a la idea de llevar una idea articulada a la noción de dar un salto de la lucha económica.

"Creo que [muchos docentes compañeros] lo ven o lo sienten como que los gobiernos hacen lo que pueden como que nadie quiere hacerte el mal...no?, y uno ya en el haberse interiorizado en algunas cosas dice jestos tipos no están gobernando para nosotros!, estos están gobernando para los grandes empresarios (...) pero son escalones en la conciencia de clase de cada uno, de la experiencia que va haciendo en su vida (...) en las asambleas mucha gente se enoja cuando se habla de política ¿no?, debería ser todo lo contrario, porque estamos discutiendo política..." ${ }^{23}$.
Iván le da sentido al ataque sobre la política en al ámbito educativo como un elemento de la distorsión proporcionada por los grandes medios de comunicación y de los partidos patronales, de toda una situación heredera del 2001, "ya que lo que quieren las clases dominantes es negarle al trabajador cualquier posibilidad de organizarse políticamente y tener una opción política para dar pelea por la conciencia y por dar una política revolucionaria". Desde su postura lo reivindicativo meramente es un problema, porque la resolución está en la unidad de los problemas que aquejan a los trabajadores, para generar una conciencia superior que identifique el problema de clase ${ }^{24}$.

Para Alejandra estas susceptibilidades en el común del trabajador docente son temas profundamente complicados, ¿es posible generar una verdadera conciencia de lucha sólo con el paro como herramienta colectiva? ¿son las jornadas de protesta y la acciones gremiales mecanismos disparadores de un verdadero plan de lucha?... Desde su punto de vista el conflicto debe siempre articularse con las comunidades educativas, poner al frente el problema cotidiano como un problema político.

En este sentido todos coinciden en que las estrategias de concientización y masificación de un plan de acción enraízan directa o indirectamente en los lugares de trabajo. Y que la identificación de un docente con la lucha nace de la comprensión del fenómeno estatal como condicionante, limitante y factor estratégico de la problemática laboral cotidiana. Como expresa contundentemente Iván, "[Los docentes] tenemos que ser ese puente con la comunidad, porque ellos [los padres], son los mismos que sufren las mismas políticas del gobierno, tarifazos, los despidos, bajos salarios, el trabajo en negro, ellos lo viven y nosotros somos los maestros de sus hijos... que también van a ser futuros proletarios y futuros explotados de este sistema..." ${ }^{25}$.

\section{Dimensión 4: ¿profesionales o trabajadores?}

A los docentes se los ha definido históricamente como un conjunto de intelectuales al servicio del Estado que responden a la formación de determinados contenidos programados en un curriculum educativo. Sin embargo, esta mirada fue cambiando para dar paso a la identificación del docente como trabajadores que se ven investidos por la particularidad de no crear un producto específico y directo a diferencia de los obreros industriales. En los docentes la subsunción (es decir la forma de explotación) del trabajo es formal y no es real. El

21. Entrevista a Alejandra, ídem.

22: Entrevista a Marcos, realizada por PB, 15 de mayo de 2018.

23: Entrevista a Marcos, ídem.

24: Entrevista a Iván, ídem.

25: Entrevista a Iván, ídem. 
proceso de trabajo es controlado parcialmente por el Estado provincial o nacional, por lo que la experiencia de alienación no es directamente vivenciable como en otros sectores obreros. Para los trabajadores docentes esa situación se complejiza y hace que las políticas patronales se encuentren triplemente mediadas: ideológica, profesional y organizacionalmente. La percepción misma de la patronal es poco nítida para el conjunto docente y se encuentra teñida de definiciones sobre la burocracia administrativa (Rodriguez, Soul y Gindin, 2004).

La idea profesionalizante es una identidad construida bajo la premisa de que el docente al ser empleado para educar al ciudadano, su imagen se encuentra mediada por el Estado como representante de la comunidad nacional que contrata al trabajador para una tarea de importancia social. Por otra parte, si bien en la actualidad la proletarización de la actividad se encuentra en alza (Donaire, 2009), los docentes todavía mantienen cierta autonomía y control sobre su propio trabajo. Aquí es donde abreva la imagen profesional del docente, como el intelectual capacitado didácticamentey por la teoría pedagógica para dar clase. En este sentido, la contratación docente y el régimen de trabajo se encuentra centralizados, y se dispone que la carrera docente se encuentre reglamentada bajo estrictos controles que posibiliten el ascenso a cargos directivos y de supervisores, lo que constituye una mediación organizacional para las políticas del sector. La competencia se introduce fuertemente entre pares como entre las propias escuelas por captar recursos.

Iván lo expresa como una conciencia que da saltos en determinados momentos de la conflictividad social:

Yo creo que hay un sector importante de docentes que se creen de una clase superior, y otros te dicen que son de la clase media (...) hay un sector docente que no está ligado a la producción material y eso es difícil de verlo, vos en una fábrica ves al patrón y en la docencia cuesta (...) Es difícil que en general haya un sector que se identifique con los obreros, pero tiene que ver con las situaciones, hay veces que la conciencia te hace dar saltos y te lleva a repensar tu posición y otras veces no, te lleva a una anti- política, que surgen en los momentos de mayor quietud... eso es medio movible cuando hay momentos de tensión y movilización se sale más como trabajador (... ${ }^{26}$.
A Daniela le molestan que le pregunten como "colega", porque desvirtúa el sentido de pertenencia como trabajador de la educación. Sin embargo en algunos momentos del enfrentamiento docente/ gobierno este supuesto profesionalizante florece y más cuando los docentes son objetos y no sujetos de políticas públicas como dice Analía, o cuando intentan ser reemplazados por "ciudadanos voluntarios" 27. Marcelo lo sintentiza de otra forma y según su visión ser profesional es una cuestión de status y tampoco se siente trabajador, sino que su elección fue la de ser maestro:

“(...) yo me reconozco así (...) esto que elegí es lo que quiero y me da bronca la situación en la que te hacen vivir (...) yo sufro mucho cuando a los docentes nos tildan de vagos, porque la realidad no es esa...a mi de duele porque soy consciente de lo que hago, se las horas que invierto, la plata que invierto ,lo que renuncio, eso escucharlo es chocante... la realidad es difícil (...) hay que hablar con honestidad y explicarles a los padres porque hacemos paro, y que pensamos de nuestros chicos" ${ }^{28}$.

Las reformas estatales interpelan al docente en su saber y responsabilidad profesional al mismo tiempo que de hecho aumentan el control y descalifican su tarea, lo que tiene grandes consecuencias sobre la salud de los trabajadores ya que estos terminan haciéndose cargo del funcionamiento de las escuelas en pésimas condiciones.

\section{CONCLUSIONES}

Este trabajo de investigación sobre los sentidos que portan los docentes en la actualidad se basa principalmente en trayectorias locales dentro de un periodo histórico reciente. La situación docente, atravesada por múltiples demandas en medio de una situación de deterioro social, contiene en la propia organización de la conflictividad un sinnúmero de posibilidades de enseñanza y aprendizaje significativos. Los sujetos se sienten parte de colectivos que los invitan a compartir sus problemas, a sentirse contenidos y a pensar estrategias que visibilicen sus necesidades. Las prácticas sindicales forman parte de un conjunto de lógicas que reformulan aspectos claves de la organización colectiva y sirven como herramientas de cambio en las propias prácticas cotidianas, cuando posibilitan la participación democrática.

26: Entrevista a Iván, ídem.

27: El gobierno de la provincia de Buenos Aires durante los primeros meses del año 2017 abrió un registro en la página oficial del ministerio de educación para permitir la inscripción de voluntarios que quisieran dar clases en escuelas públicas, frente al paro docente. Los gremios salieron al cruce de las declaraciones de la gobernadora María Eugenia Vidal, con recursos de amparo que finalmente hicieron retroceder la medida (Debesa, 2017: 4).

28: Entrevista a Marcelo, ídem. 
El proceso de conflictividad docente arroja una serie de incentivos para generar marcos de identificación social que se basan en múltiples formas donde predomina el sentido de clase social. A pesar de las contradicciones propias de la percepción de clase del docente, la relación fuertemente edificada en relación a una situación de empobrecimiento demuestra que las situaciones de proletarización docente impactan fuertemente en los sentidos construidos alrededor de la propia labor.

Entre las afirmaciones que se plantean en este estudio es que las experiencias docentes en torno al sindicato analizado recuperan las relaciones entre aspectos subjetivos y objetivos en la formación de la clase trabajadora, a partir del reconocimiento de sí mismos como un colectivo político que, formando parte de la sociedad civil, disputa un proyecto contra hegemónico en el que se busca recuperar una dimensión de totalidad. Esto significa, en el caso de los docentes, reconocerse como intelectuales y entender que en la praxis política se imbrican aspectos políticos, pedagógicos, culturales y económicos. La lucha por la educación pública, gratuita, inclusiva y laica fueron banderas predominantes en los significantes que movilizan la conflictividad docente.

La descripción y posterior categorización de los elementos comunes y diferenciables que surgen de las entrevistas nos invitan a reflexionar sobre algunas cuestiones importantes dentro del mundo docente. Por empezar los procesos de politización son diversos y encuentran en las trayectoria de los individuos formas interesantes de expresarse. Aparece en todos los relatos una sintonía especial con otros militantes o referentes que invitan a los mismos a comenzar a participar lentamente de actividades políticas. En algunos casos proviene de su formación académica y en otros fuertemente asociados a otras instituciones como la iglesia. En este sentido la vocación no aparece como una regla que permita ser un factor de estímulo para la militancia política.

Por otra parte las condiciones de trabajo y la precarización aparecen como elementos a definir que tienen una fuerte carga de variación de acuerdo a las experiencias propias de los sujetos. La mayoría vivenció las problemáticas propias de la escuela pública, pero en general la precarización pasa antes que por la decadencia salarial por la desvalorización del trabajador docente.

El sindicato y las prácticas sindicales ocupan buena parte de las reflexiones de los militantes de organizaciones gremiales que disputan poder dentro del mismo. En este sentido sobresale la idea de solidaridad, de praxis basada en la horizontalidad y la democracia, que intentan contraponerse a un estilo histórico en el que se ha desarrollado el sindicalismo en general. En este sentido la atención al delegado y el esfuerzo por no caer en decisiones burocráticas, la falta de relación dirigentes- bases y la percepción de los intereses de los afiliados y no afiliados en determinados momentos coyunturales han sido cuestiones permanentemente atendidas. Las huelgas docentes y las manifestaciones pasan a articularse como un elemento interesante dentro del repertorio de acción colectiva, donde se buscan las formas de estimular la conciencia de otros trabajadores de la educación, así como renovarlas con el fin de generar más empatía social.

Por último adquiere importancia la cuestión de las asambleas y el partidismo dentro del propio sindicato como formas en las que se expresan tensiones que combinan el ámbito reivindicativo, propio del docente común, con el ámbito del militante y su búsqueda incesante de vinculación con el contexto político. Aquí se expresa la comprensión de qué tipo de organización sindical se busca propiciar, donde la confrontación entre diversos sentidos y prácticas militantes no siempre se vuelca con éxito sobre el común de la base docente. 


\section{BIBLIOGRAFÍA}

Becher, P (2018), El movimiento de trabajadorxs desocupadxs en Bahía Blanca, Acercándonos edicionesCEISO, Bahía Blanca

Blanco, A. (2010), "La construcción de espacios de organización política de los docentes: el desafío que representa el encuentro colectivo de la provincia de Buenos Aires" en Associaçoes e Sindicatos de Trabalhadores em Educaçao, Rio de Janiero, 22 y 23 de abril.

Chiappe, M. y Spaltenberg, R. (2010), Una aproximación a los conflictos laborales del sector docente en Argentina durante el período 2006-2009, Universidad Nacional de Rosario

Centro Regional de Estudios Economicos Bahía Blanca (CREEBBA) (2016), “El aporte del sector educativo a la economía local", en Indicadores de actividad económica, no 145. Recuperado de: http://www.creebba.org.ar/ iae/iae145/El_aporte_del_sector_educativo_a_la_ economia_local_IAE_145.pdf

Cyunel, V. y Montenegro Loewy, L. (2015), “Conflictos laborales y disputas sindicales en el sector de la enseñanza estatal provincial. Algunas consideraciones teórico-metodológicas", en Actas del Congreso Nacional de Estudios del Trabajo, ASET, Buenos Aires, Agosto de 2015.

Donaire, R. (2009): La posición social de los docentes en la actualidad. Una aproximación a partir del estudio de los docentes de la Ciudad de Buenos Aires, Tesis de Doctorado en Ciencias Sociales, UBA, Buenos Aires.

Gentili, P., Suarez, D., Stubrin, F. y Gindín, J. (2004), "Reforma educativa y luchas docentes en América Latina", en Educaçao y Sociedade , Campinas, 89 (25), pp: 1251- 1274.

Gentili, P. (2013), Desencanto y utopía. La educación en el laberinto de los nuevos tiempos, CLACSO, Caracas.

Gindin, J. (2008): "Sindicalismo docente en América Latina: algunas consideraciones generales" y "Sindicalismo docente en Argentina: una nueva etapa", en Sindicalismo docente en América Latina. Experiencias recientes en Bolivia, Perú, México, Chile y Argentina (Gindin comp.), Rosario: Ediciones de AMSAFE Rosario.
Jaimovic, A., Migliavacca, A., Pasmanik, Y. y Safocarda, F. (2004), Reformas neoliberales, condiciones laborales y estatutos docentes, Centro Cultural de Cooperación: Ciudad Buenos Aires.

López, E. y Cantamutto, F. (2013), “Las demandas económicas de la clase trabajadora en el nuevo modo de desarrollo argentino (2002-2011), en Conflicto social (6) 10, pp: 47- 72.

Migliavacca, A. (2009): La protesta docente en la década de 1990. Experiencias de organización sindical en la provincia de Buenos Aires, Tesis de Maestría en Política y Gestión de la Educación, Luján: Universidad Nacional de Luján.

Narodowsky, M. (1996): "El lado oscuro de la luna”, en Historia de la Educación en debate (Cucuzza comp.). Buenos Aires: Miño y Dávila.

Neffa, J., Brown, B.y López, E. (2010), Empleo, desempleo, y políticas de empleo, CEIL- CONICET, Buenos Aires. Retamozo, Martín (2007), “Los sentidos del (sin) trabajo. Subjetividad y demanda en el movimiento de trabajadores desocupados en Argentina", en Sociohistórica, n²1- 22, La Plata, pp: 55- 90.

Rodriguez, G., Soul, J. y GIndin, J. (2004), “Políticas de organización gremial en Rosario. Las experiencias de docentes y mercantiles", en Estudios de trabajo, ASET, pp: 57- 87.

Petruccelli, A. (2005): Docentes y piqueteros. De la huelga de ATEN a la pueblada de Cutral Có. Buenos Aires: El cielo por asalto / El Fracaso.

Svampa, M. (2008), Cambio de época: movimientos sociales y poder político, Ed. El Colectivo, Buenos Aires.

Tedesco, J.yE.Tenti Fanfani, (2001), “La reforma educativa en la Argentina. Semejanzas y particularidades", en Proyecto Alcance y resultados de las reformas educativas en Argentina, Chile y Uruguay Ministerios de Educación de Argentina, Chile y Uruguay, Grupo Asesor de la Universidad de Stanford/BID.

Vasilaschis, I. (2007), Estrategias de investigación cualitativa. Buenos Aires: Gedisa. 


\section{Artículos de periódicos}

Carabajal Figueroa, N. (23 de agosto de 2001), "Padres Docentes y alumnos, una clase magistral, Diario Eco Días, pp: 4- 5.

Debesa, F. (3 de marzo de 2017), "Maestros voluntarios: crece la polémica por la iniciativa oficial", Diario Clarín, p. 4. Recuperado de: https://www.clarin.com/sociedad/ maestros-voluntarios-crece-polemica-iniciativaoficial_0_Syl3PVL9x.html

Rezzuti, W. (21 de septiembre de 2001), "Marcha Nacional contra el ajuste y a favor de la educación pública y gratuita", Diario Eco Días, p. 4.

"El segundo escuelazo bahiense",(23 de agosto de 2001), La Nueva Provincia, pp: 4-5

"Padres y docentes censuran los acuerdos de SUTEBA" (30 de agosto de 2001), La Nueva Provincia, p. 6. 